\title{
Rendimento de grãos de pinhão-manso submetido a diferentes níveis de irrigação e adubação potássica
}

\author{
Jatropha grain yield under different irrigation and potassium fertilization levels \\ F. P. de Deus*, M. A. de Faria, A. V. Diotto \\ ${ }^{1}$ Universidade Federal de Lavras, Brasil
}

fabio.ponciano@deg.ufla.br

(Recebido em 17 de agosto de 2016; aceito em 21 de novembro de 2016)

\begin{abstract}
Dentre as diversas espécies vegetais oleaginosas, o pinhão-manso se destaca em razão da possibilidade de alcance de altos índices de produtividade e qualidade do óleo. Apesar desse potencial produtivo, existem muitas incertezas com relação aos aspectos agronômicos que interferem na produção, impossibilitando um investimento financeiro confiável. Nesse sentido, o objetivo deste trabalho foi avaliar o segundo ano de produção de grãos de pinhão-manso, em função da diferenciação de lâminas de irrigação e doses de potássio, na cidade de Lavras, sul do Estado de Minas Gerais. Para isso, um experimento foi delineado em blocos casualizados, em esquema de parcelas subdivididas, com quatro repetições. Aplicaram-se quatro lâminas de irrigação com base na porcentagem do saldo entre a evaporação acumulada do tanque Classe A (ECA) e as precipitações, sendo as seguintes: L0 - sem irrigação, e L40, L80 e L120, como sendo 40, 80 e $120 \%$ do saldo respectivamente, e quatro doses de potássio que foram de: K30 - 30; K60 - 60; K90 - 90; e $\mathrm{K} 120$ - $120 \mathrm{~kg} \mathrm{ha}^{-1}$, aplicadas via água de irrigação por gotejamento. Os resultados mostraram que a utilização da irrigação proporcionou efeito significativo na produtividade e na eficiência no uso da água do segundo ano de produção de grãos de pinhão-manso. Os tratamentos referentes à dosagem de potássio não influenciaram significativamente a produtividade de grãos, no entanto influenciaram a eficiência no uso da água, atingindo valor máximo quando se utilizou a dosagem de $120 \mathrm{~kg} \mathrm{ha}^{-1}$.

Palavras-chave: biodiesel, oleaginosa, manejo da irrigação.
\end{abstract}

Among the various oil plant species, the Jatropha stands out because of the possibility of achieving high levels of productivity and quality of oil. Although this productive potential, there are many uncertainties regarding the agronomic aspects that interfere in the production, making it impossible a secure financial investment. In this sense, this work aim was to evaluate the second year of jatropha grain production, under different irrigation and potassium levels, in Lavras, south of Minas Gerais State, Brazil. The experimental design was randomized blocks, in spit plot design, with four replicates. It was applied four irrigation levels based on the water balance between the class A pan evaporation (ECA) and rain depths - L0 (rainfed), L40, L80 and L120 (40, 80 and 120\% of the water balance respectively), and four potassium levels: K30, K60, $\mathrm{K} 90$ and $\mathrm{K} 120$ (30, 60, 90 and $120 \mathrm{~kg} \mathrm{ha}^{-1}$ of potassium, respectively), applied by drip fertigation. The irrigation levels showed significant effect in productivity and water use efficiency for the second growing year of jatropha. The potassium dosage treatments do not affect significantly the productivity, however influenced the water use efficiency, reaching maximum value using $120 \mathrm{~kg} \mathrm{ha}^{-1}$ of potassium.

Keywords: biodiesel, oilseed, irrigation management.

\section{INTRODUÇÃO}

As matérias primas de origem fóssil ainda compõem as principais fontes para a produção de energia no mundo. Entretanto, a previsão de esgotamento de suas reservas, as oscilações de preço no mercado e as mudanças climáticas mundiais devem intensificar a sua substituição por fontes renováveis e mais limpas [25]. Nesse sentido, o uso do biodiesel como fonte alternativa de combustível é uma opção em potencial, pois utiliza óleos vegetais e/ou gorduras animais para a sua produção, apresentando as características de ser biodegradável e não tóxico, com menores emissões de gases quando comparado aos combustíveis de origem fóssil [14]

O Brasil possui grande diversidade de espécies vegetais oleaginosas que podem fornecer a matéria prima para a produção de biodiesel e dentre as muitas se destaca o pinhão-manso. $\mathrm{O}$ pinhão-manso é uma planta arbustiva pertencente à família das Euphorbiaceae, gênero Jatropha, 
e espécie Jatropha curcas L., sendo considerada por muitos autores como uma cultura rústica, que se adapta a diferentes condições edafoclimáticas, apesar de exigir água e solos com boa fertilidade para atingir altos índices de produtividade e qualidade do óleo em condições de plantio comercial $[2 ; 12 ; 21 ; 17]$.

Apesar do potencial econômico do pinhão-manso, existem muitas incertezas no que tange aos aspectos agronômicos, impossibilitando muitas vezes a tomada de decisão sobre o investimento financeiro. O comportamento das variáveis de crescimento e de produção em função das exigências hídricas e nutricionais são questões que exigem estudos comprobatórios para nortear as decisões nos sistemas produtivos $[20 ; 22 ; 5]$.

A produtividade do pinhão-manso é muito variável, dependendo diretamente da região, do método de cultivo, dos tratos culturais, da regularidade pluviométrica e da fertilidade do solo [16]. A idade produtiva do pinhão-manso é atingida entre três e quatro anos, estendendo-se por 40 anos, com produtividade mínima de $2000 \mathrm{~kg} \mathrm{ha}^{-1}$ de óleo [3], ou seja, considerando um teor médio de óleo de 33\% [7], ter-se-ia uma produtividade de sementes em torno de $6000 \mathrm{~kg} \mathrm{ha}^{-1}$. Já no segundo ano é possível obter uma produtividade de sementes de $2000 \mathrm{~kg} \mathrm{ha}^{-1}$ [19].

Em se tratando do comportamento produtivo da cultura em função da irrigação, é relatado que a cultura responde muito bem à irrigação, afetando de forma direta na produtividade, possibilitando de três a quatro colheitas por ano [18]. Esse fato também foi observado em outros trabalhos $[4 ; 9 ; 17]$. Em trabalho realizado em Petrolina (PE), já no primeiro ano foram observadas produtividades de sementes de $1200 \mathrm{~kg} \mathrm{ha}^{-1}$ para cultivo irrigado, e $330 \mathrm{~kg} \mathrm{ha}^{-1}$ para a cultura na condição de sequeiro [8]. Em uma ampla revisão sobre a cultura, observa-se relatos da possibilidade de variação na produtividade entre 1500 a $10000 \mathrm{~kg} \mathrm{ha}^{-1} \mathrm{ano}^{-1}$, apresentando como principal problema para as baixas produtividades, a pouca ou nenhuma seleção genética e as limitações de água e nutrientes [10].

Com relação à adubação, verificou-se em folhas de pinhão-manso uma relação entre nitrogênio e potássio de 2,3, e nos frutos em torno de 1,4 [12]. Isso indica que na fase de produção da cultura há aumento do requerimento por potássio, possivelmente exercendo papel significativo na formação dos frutos e na produção, atuando no transporte de fotoassimilados. Outra evidência da importância do potássio na produção de frutos de pinhão-manso está no relato de que para produzir uma tonelada de frutos (casca+sementes), extrai-se do solo em média 22,95 $\mathrm{kg}$ de potássio; 24,3 kg de nitrogênio; e 3,85 kg de fósforo [10].

Com base no exposto acima, objetivou-se com o presente trabalho avaliar o segundo ano de produção de grãos de pinhão-manso, em função da diferenciação de lâminas de irrigação e doses de potássio, na cidade de Lavras, sul do estado de Minas Gerais.

\section{MATERIAL E MÉTODOS}

O experimento foi conduzido em área experimental do setor de Fruticultura do Departamento de Agricultura da Universidade Federal de Lavras (UFLA), em Lavras, Estado de Minas Gerais ( $21^{\circ} 14^{\prime}$ de Latitude Sul e $45^{\circ} 00^{\prime}$ de Longitude Oeste, a $892 \mathrm{~m}$ de altitude). A cidade de Lavras possui clima do tipo Cwa de acordo com classificação Koppen (clima temperado úmido com inverno seco e verão quente), com temperatura anual média do ar de $19,4^{\circ} \mathrm{C}$, umidade relativa do ar média de $76,2 \%$, precipitação média anual de $1529,7 \mathrm{~mm}$ e evaporação média anual de 1034,3 $\mathrm{mm}[6]$.

Os dados analisados no presente estudo originaram-se do segundo ano de produção de grãos de pinhão-manso, referente ao terceiro ano de idade da cultura. A formação da área experimental iniciou-se com a semeadura realizada em tubetes de $120 \mathrm{~mL}$ utilizando-se substrato comercial, de acordo com orientações da literatura [1]. Posteriormente, as mudas de pinhão-manso (Jatropha curcas L.) foram transplantadas em sulco, manualmente, no espaçamento de 3,0 m entre linhas de plantio e 1,5 m entre plantas. O solo do sulco foi classificado como sendo Argissolo Vermelho Eutrófico.

O delineamento experimental utilizado foi o de blocos casualizados, em esquema de parcelas subdivididas com quatro repetições, no qual foram aplicados quatro tratamentos de lâmina de irrigação e quatro doses de potássio. As lâminas de irrigação foram aplicadas com base na 
porcentagem do saldo entre a evaporação acumulada do tanque Classe A (ECA) e as precipitações, sendo as seguintes: L0 - sem irrigação; L40 - 40; L80 - 80 e L120 - 120\% do saldo. As doses de potássio foram aplicadas a cada ciclo de produção da cultura, na água de irrigação para as parcelas irrigadas, e manualmente para o tratamento não irrigado, nas seguintes dosagens: K30 - 30; K60 - 60; K90 - 90 e K120 - 120 kg de potássio por hectare. Procedeu-se a casualização das lâminas de irrigação dentro dos blocos (repetições), e as doses de potássio dentro de cada lâmina de irrigação, ou seja, as lâminas de irrigação foram aplicadas nas parcelas, e as doses de potássio nas subparcelas.

Procedeu-se a casualização das lâminas de irrigação dentro dos blocos (repetições) e as doses de potássio dentro de cada lâmina de irrigação, ou seja, as lâminas de irrigação foram aplicadas nas parcelas e as doses de potássio nas subparcelas. Cada parcela experimental foi constituída de seis linhas de plantio, espaçadas de $3 \mathrm{~m}$, com comprimento de $12 \mathrm{~m}$, compostas por 48 plantas com área total de $2016 \mathrm{~m}^{2}$. A área útil da parcela experimental foi de $108 \mathrm{~m}^{2}$, consideradas as 4 linhas centrais, com 16 plantas consideradas úteis. Cada linha central, com 4 plantas de pinhãomanso por linha de plantio foi considerada uma parcela útil. A Figura 1 apresenta o layout de distribuição dos tratamentos na área.

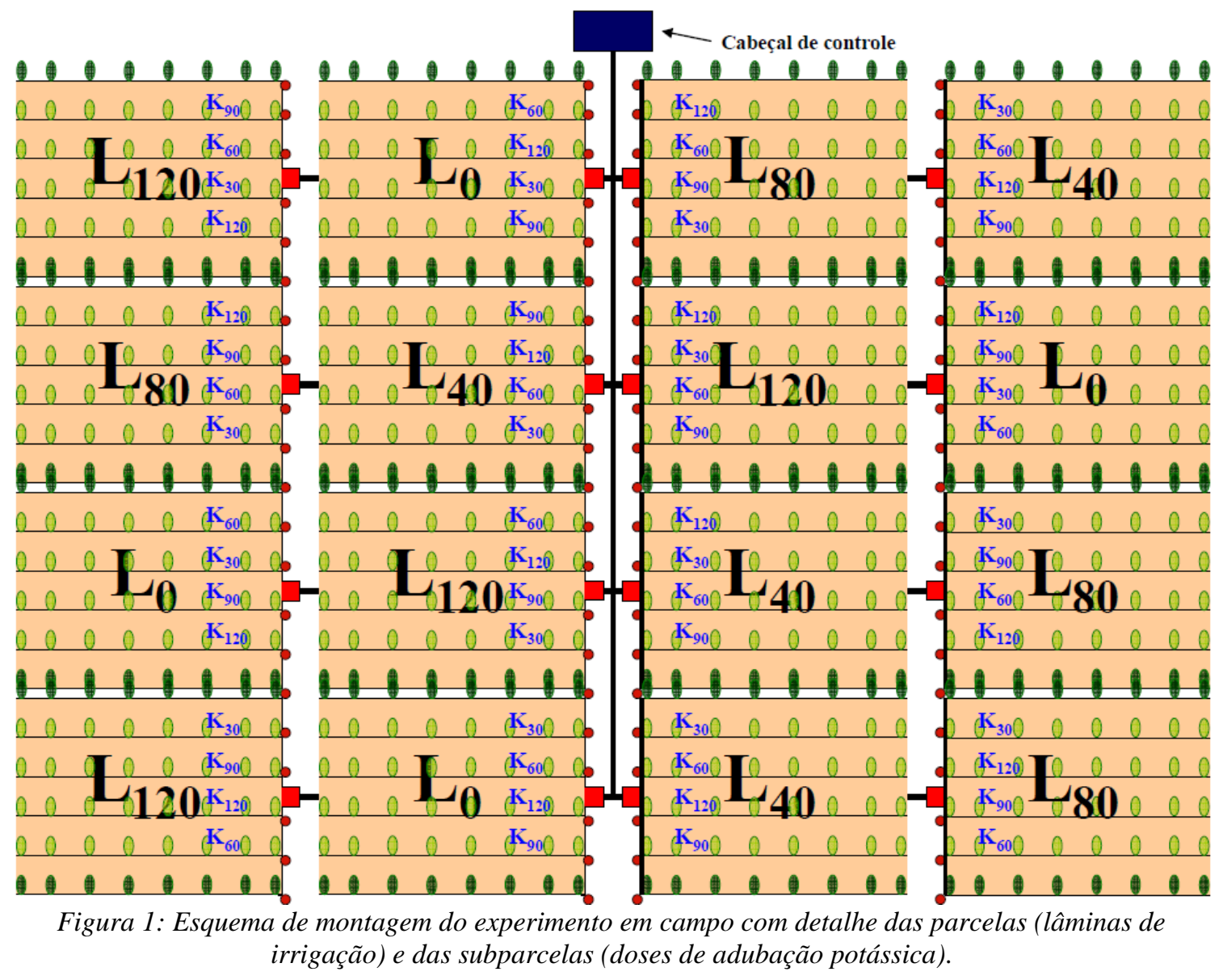

Os dados meteorológicos de evaporação do tanque classe A e precipitação foram obtidos na Estação Meteorológica Principal de Lavras - INMET ( $5^{\circ}$ Distrito de meteorologia - Belo Horizonte, MG), localizada a 300 metros da área experimental. As irrigações foram realizadas com turno de rega fixo, duas vezes por semana (terças e sextas-feiras), sendo utilizados tubos gotejadores, com emissores autocompensantes (faixa de compensação de 0,4 a $2,5 \mathrm{kgf} \mathrm{cm}^{-2}$ ) espaçados de $0,50 \mathrm{~m}$, com vazão média de $1,6 \mathrm{~L} \mathrm{~h}^{-1}$, formando uma faixa molhada contínua ao longo das linhas de plantio. O coeficiente de uniformidade de Christiansen (CUC) avaliado no início do experimento foi de $96 \%$. O tempo de irrigação foi determinado com base na equação 1 [7]. 
$T i=\frac{\left(\frac{\sum E C A-\sum P p}{E}\right) \cdot A}{q}$

Em que,

Ti - tempo de irrigação, $\mathrm{h}$;

$\sum E C A$ - somatório de evaporação do tanque classe A no intervalo entre irrigações, mm;

$\sum P_{p}$ - somatório da precipitação pluviométrica no intervalo entre irrigações, mm;

E - eficiência do sistema de irrigação considerada $(0,95)$, decimal;

A - área molhada pelo gotejador (valor estimado de $0,25 \mathrm{~m}^{2}$ ), $\mathrm{m}^{2}$;

$\mathrm{q}$ - vazão média do emissor $\left(1,6 \mathrm{~L} \mathrm{~h}^{-1}\right), \mathrm{L} \mathrm{h}^{-1}$.

A colheita das subparcelas experimentais foi realizada manualmente, sendo os frutos acondicionados em sacarias de fio plástico trançado para secagem em bancadas de madeira. Posteriormente à secagem foi determinada a umidade dos grãos, corrigindo a massa das amostras para valor de umidade de $13 \%$ na base úmida. Com base na massa de grãos corrigida foram analisadas a produtividade e a eficiência no uso da água na produção de grãos. As equações 2,3 e 4 foram utilizadas respectivamente para estimar a massa de grãos corrigida $\left(M_{\text {final }}\right)$, a produtividade $(\mathrm{P})$ e a eficiência no uso da água na produção de grãos (EUA).

$M_{\text {final }}=\frac{M_{\text {inicial }} \cdot\left(100-U_{\text {inicial }}\right)}{\left(100-U_{\text {ref }}\right)}$

Em que,

$M_{\text {final }}$ - massa corrigida de grãos para a umidade de referência, $\mathrm{kg}$;

$M_{\text {inicial }}$ - massa inicial dos grãos, $\mathrm{kg}$;

$U_{\text {inicial }}$ - umidade inicial dos grãos, \%;

$U_{\text {ref }}$ - umidade de referência para correção da massa de grãos (13\%), \%.

$P=\frac{10000 \cdot M_{\text {final }}}{e_{p} \cdot e_{l} \cdot n_{p}}$

Em que,

$P$ - produtividade de grãos para a umidade de referência, $\mathrm{kg} \mathrm{ha}^{-1}$;

$e_{p}$ - espaçamento entre plantas $(1,5 \mathrm{~m}), \mathrm{m}$;

$e_{l}$ - espaçamento entre linhas de plantio $(3,0 \mathrm{~m}), \mathrm{m}$;

$n_{p}$ - número total de plantas consideradas por tratamento (4).

$E U A=\frac{P}{L t}$

Em que,

$E U A$ - eficiência no uso da água na produção de grãos de pinhão-manso, $\mathrm{kg} \mathrm{ha}^{-1} \mathrm{~mm}^{-1}$;

$L t$ - lâminas totais relativas à água recebida por meio da irrigação e da precipitação, $\mathrm{mm}$.

Os dados foram analisados estatisticamente pela análise de variância e aqueles fatores que apresentaram diferença significativa $(\mathrm{P}<0,05)$ foram feitos ajustes de equações utilizando análise de regressão. O software Sisvar versão 5.3 foi utilizado para auxiliar nas análises estatísticas.

\section{RESULTADOS E DISCUSSÃO}

A Tabela 1 apresenta a quantidade de água recebida pela cultura do pinhão-manso por irrigação e seu somatório com a precipitação pluviométrica, referente ao segundo ano de produção da cultura. 
Tabela 1: Quantidade de água recebida pela cultura do pinhão-manso por irrigação e total (irrigação + precipitação pluviométrica) no segundo ano de produção.

\begin{tabular}{ccc}
\hline \multirow{2}{*}{ Tratamento de irrigação } & \multicolumn{2}{c}{ Precipitação pluviométrica total anual $-(\mathrm{Pp}=1625,80 \mathrm{~mm})$} \\
\cline { 2 - 3 } & Lâmina de irrigação - LI $(\mathrm{mm})$ & Lâmina total de água $-\mathrm{Lt}(\mathrm{mm})$ \\
\hline L0 & 0 & 1625,80 \\
L40 & 398,62 & 2024,42 \\
L80 & 797,24 & 2423,04 \\
L120 & 1195,86 & 2821,66 \\
\hline
\end{tabular}

As referidas lâminas de irrigação foram aplicadas no período compreendido entre abril e novembro, como demonstrado na Figura 2, que representa a distribuição temporal da evaporação do tanque classe A e da precipitação. Essa informação está de acordo com a literatura [6], que relata que a estação chuvosa de Lavras se estende de outubro a março, e a estação seca compreende os meses de abril a setembro.

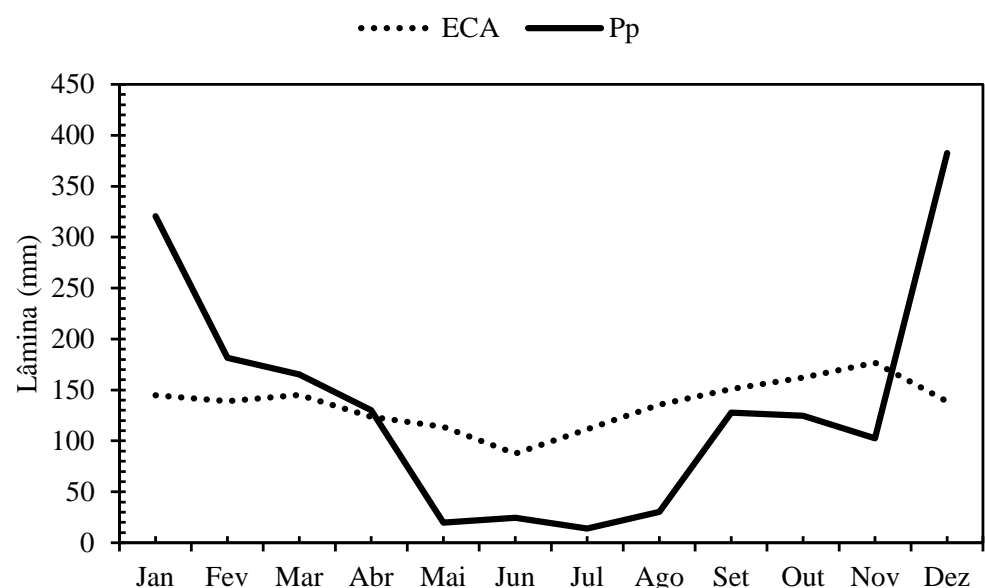

Figura 2: Distribuição mensal da evaporação do tanque classe A (ECA) e da precipitação pluviométrica (Pp) para o segundo ano de produção de grãos de pinhão-manso.

O balanço entre a ECA e a precipitação para o segundo ano de produção mostra um déficit hídrico médio de $495 \mathrm{~mm}$ para o período de maio a novembro, e um excedente hídrico médio de $489 \mathrm{~mm}$ para o período de dezembro a abril. Nesse sentido, mesmo a cidade de Lavras-MG (sul de Minas Gerais), apresentando precipitação média anual acima de $1000 \mathrm{~mm}$ [6], o prolongado período de seca pode determinar o comprometimento da produtividade de culturas não irrigadas. Alguns autores salientam que a disponibilidade de água é um dos fatores mais importantes no desenvolvimento e na produtividade de sementes e óleo de plantas oleaginosas [11].

Os resultados da análise de variância dos dados de produtividade $(\mathrm{P})$ e eficiência no uso da água para a produção de grãos (EUA) estão dispostos na Tabela 2. Na tabela 3 apresentam-se os resultados da análise de regressão para os parâmetros que se apresentaram significativos pelo teste $\mathrm{F}(\mathrm{P}<0,05)$. 
Tabela 2: Análise de variância para produtividade de grãos $(P)$ e eficiência no uso da água (EUA) para o segundo ano de produção de grãos de pinhão-manso

\begin{tabular}{cccc}
\hline \multirow{2}{*}{ Fonte de variação } & $\begin{array}{c}\text { Grau de } \\
\text { liberdade }\end{array}$ & $\begin{array}{c}\text { Produtividade - P } \\
\left(\mathrm{kg} \mathrm{ha}^{-1}\right)\end{array}$ & $\begin{array}{c}\text { Quadrado médio } \\
\text { Eficiência no uso da água - EUA } \\
\left(\mathrm{kg} \mathrm{ha}^{-1} \mathrm{~mm}^{-1}\right)\end{array}$ \\
\hline Lâmina & 3 & $5,17.10^{5 *}$ & $0,114^{*}$ \\
Resíduo 1 & 9 & $5,59.10^{4}$ & 0,0089 \\
Potássio & 3 & $2,65.10^{5} \mathrm{~ns}$ & $0,056^{*}$ \\
Interação & 9 & $5,41.10^{4} \mathrm{~ns}$ & $0,0099 \mathrm{~ns}$ \\
Resíduo 2 & 36 & $8,38.10^{4}$ & 0,0167 \\
Total & 60 & - & - \\
Média Gral & - & 1063,35 & 0,49 \\
CV $_{1}$ & - & 22,25 & 19,36 \\
$\mathrm{CV}_{2}$ & - & 27,24 & 26,49 \\
\hline
\end{tabular}

ns: não significativo; *: significativo a 5\% de probabilidade; CV: coeficiente de variação (\%).

Observa-se que a interação da lâmina e adubação potássica não influenciou significativamente a produtividade $(\mathrm{P})$ nem a eficiência no uso da água na produção de grãos (EUA). Por outro lado, analisando de forma isolada os fatores de variação, observou-se que o tratamento de lâmina influenciou tanto a produtividade quanto a EUA, e com relação à adubação potássica observou-se influência apenas para a EUA. Em alguns trabalhos também foi observado efeito significativo da irrigação na produtividade de grãos de pinhão-manso, contudo esta foi observada para o primeiro ano de produção [9; 24]. Com relação à adubação potássica, apesar e alguns trabalhos relatarem não haver influência significativa na produtividade de grãos de pinhão-manso [16], outros observaram efeito significativo do uso da adubação potássica na produtividade de grãos da cultura [24].

Tabela 3: Análise de regressão para produtividade de grãos $(P)$ e eficiência no uso da água para produção de grãos de pinhão-manso (EUA)

\begin{tabular}{|c|c|c|c|c|}
\hline \multirow{3}{*}{ Modelo } & \multirow{3}{*}{$\begin{array}{l}\text { Grau de } \\
\text { liberdade }\end{array}$} & \multicolumn{3}{|c|}{ Quadrado Médio } \\
\hline & & \multirow{2}{*}{$\begin{array}{c}\begin{array}{c}\text { Produtividade }-\mathrm{P} \\
\left(\mathrm{kg} \mathrm{ha}^{-1}\right)\end{array} \\
\text { Lâmina de irrigação } \\
\text { - LI }\end{array}$} & \multicolumn{2}{|c|}{$\begin{array}{l}\text { Eficiência no uso da água - EUA } \\
\qquad\left(\mathrm{kg} \mathrm{ha}^{-1} \mathrm{~mm}^{-1}\right)\end{array}$} \\
\hline & & & $\begin{array}{l}\text { Lâmina total de } \\
\text { água - Lt }\end{array}$ & Potássio \\
\hline Linear & 1 & $604975,5^{*}$ & $0,1445^{*}$ & $0,122^{*}$ \\
\hline Polinomial de $2^{\circ}$ grau & 1 & $601780,3^{*}$ & $0,1089 *$ & $0,011 \mathrm{~ns}$ \\
\hline Raiz quadrada & 1 & $344982,9 \mathrm{~ns}$ & $0,088 \mathrm{~ns}$ & $0,034 \mathrm{~ns}$ \\
\hline Resíduo & 57 & 84295,18 & 0,0089 & 0,0167 \\
\hline Total & 60 & - & - & - \\
\hline
\end{tabular}

ns: não significativo; *: significativo a 5\% de probabilidade.

Estatisticamente constatou-se que a equação quadrática foi a que melhor se ajustou aos dados de produtividade e eficiência no uso da água em função da diferenciação dos tratamentos de lâmina (Figura 3). O ponto de máxima produtividade $\left(1210,32 \mathrm{~kg} \mathrm{ha}^{-1}\right)$ foi alcançado irrigando a cultura com uma lâmina calculada de aproximadamente $80 \%$ do saldo entre a ECA e a precipitação, ou seja, aplicando uma lâmina de $790 \mathrm{~mm}$. Em avaliação da influência da lâmina de irrigação no primeiro ano de produção de grãos de pinhão-manso para a mesma área experimental também constataram efeito quadrático da lâmina de irrigação na produtividade, com ponto máximo em torno de $192 \mathrm{~kg} \mathrm{ha}^{-1}$ [16]. Comparando o ponto de máxima produtividade entre o primeiro e o segundo ano de produção observa-se um incremento de 530\%. Outros autores também observaram influência da irrigação na produtividade de grãos de pinhão-manso no semiárido cearense, onde o maior valor de produtividade do primeiro ano de produção $(270,51 \mathrm{~kg}$ 
$\mathrm{ha}^{-1}$ ) foi atingido com o maior percentual da evaporação do tanque classe - ECA (150\% de ECA), equivalente à $1647 \mathrm{~mm}$ [4].

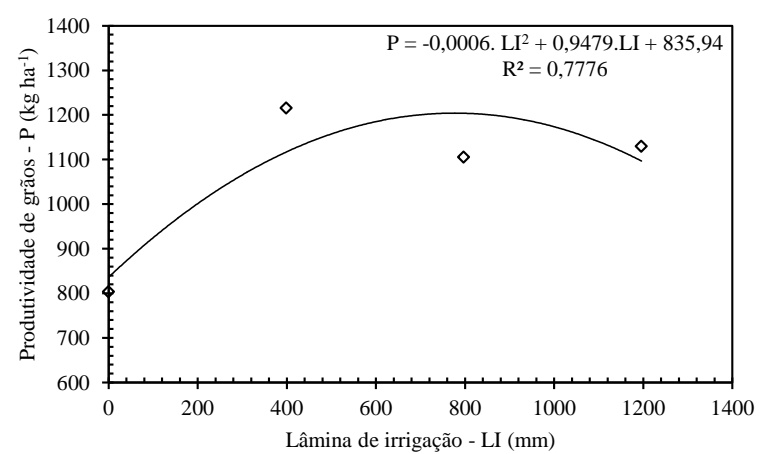

(A)

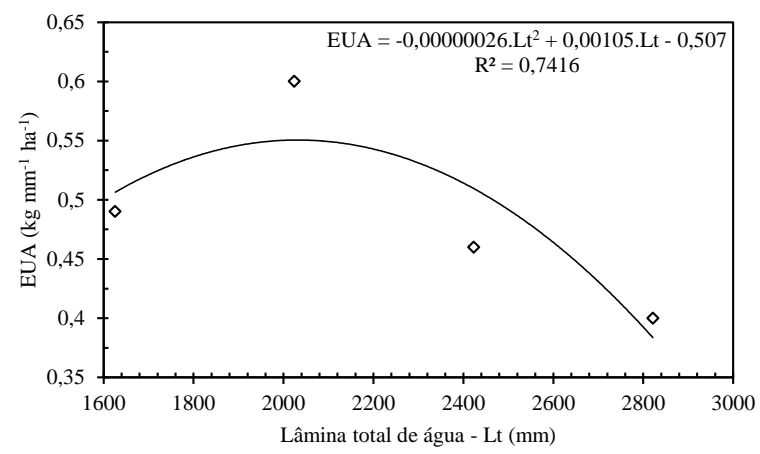

(B)

Figura 3: Representação gráfica e equação de regressão da produtividade de grãos (A) e eficiência no uso da água na produção de grãos de pinhão-manso $(B)$ em função das lâminas de irrigação e das lâminas totais de água, respectivamente.

Comparando a produtividade média atingida sem irrigação $\left(835,94 \mathrm{~kg} \mathrm{ha}^{-1}\right)$ ao ponto de máxima produtividade $\left(1210,32 \mathrm{~kg} \mathrm{ha}^{-1}\right)$, observa-se um incremento de $44,78 \%$, valor menor ao encontrado no primeiro ano de produção (69\%) [16] na mesma área experimental.

Os valores de produtividade encontrados na literatura são bastante variáveis: Alguns relatam um potencial produtivo de grãos de pinhão-manso de $6400 \mathrm{~kg} \mathrm{ha}^{-1}$ [2]. Em condições de cultura estabelecida, pode-se atingir uma produtividade média de grãos de $5000 \mathrm{~kg} \mathrm{ha}^{-1}$ [23]. Alguns autores obtiveram produtividades variando de $330 \mathrm{~kg} \mathrm{ha}^{-1}$ (sequeiro) a $1200 \mathrm{~kg} \mathrm{ha}^{-1}$ (com irrigação) já no primeiro ano de produção da cultura em Petrolina, PE [8]. Já alguns observaram uma produtividade média de $2000 \mathrm{~kg} \mathrm{ha}^{-1}$ no primeiro ano de produção (segundo ano de cultivo) [19], e outros afirmam poder alcançar produtividades em sequeiro em torno de 500 e $975 \mathrm{~kg} \mathrm{ha}^{-1}$ para o primeiro e segundo ano de produção respectivamente [13], valor próximo ao atingido na condição de sequeiro desse experimento para o segundo ano de produção $\left(835,94 \mathrm{~kg} \mathrm{ha}^{-1}\right)$.

Observou-se no experimento que o incremento na disponibilidade de água estimulou o desenvolvimento vegetativo vigoroso da planta. Em um experimento que trabalharam na mesma área experimental observaram-se plantas com altura média em torno de $2,70 \mathrm{~m}$ e incremento linear da altura com o aumento da lâmina de irrigação [16]. Além da interferência do desenvolvimento vegetativo da cultura na produção, o pinhão-manso pode apresentar redução da produtividade em razão do seu auto sombreamento, que é função da associação entre altura e espaçamento entre plantas [12].

Com relação à EUA em função da lâmina total de água aplicada (Figura 3), seu ponto de máxima $\left(0,553 \mathrm{~kg} \mathrm{ha}^{-1} \mathrm{~mm}^{-1}\right)$ foi alcançado utilizando-se o tratamento de irrigação referente à aproximadamente $40 \%$ do saldo entre a ECA e a precipitação, totalizando uma lâmina de água aplicada (irrigação + precipitação) de 2019,23 mm (393,43 mm de irrigação e $1625,8 \mathrm{~mm}$ de chuva). Em comparação ao tratamento não irrigado $\left(0,507 \mathrm{~kg} \mathrm{ha}^{-1} \mathrm{~mm}^{-1}\right)$, observa-se um incremento de $9,07 \%$. Adotando-se para o segundo ano de produção de pinhão-manso $40 \%$ do saldo entre a ECA e a precipitação $(393,43 \mathrm{~mm})$, se teria uma economia de água de aproximadamente $50,2 \%$, quando comparada à lâmina de irrigação referente ao ponto de máxima produtividade ( $80 \%$ do balanço de ECA e as precipitações $=$ total de $790 \mathrm{~mm}$ ).

Com relação ao fator adubação potássica, observou-se haver influencia apenas para a EUA, com aumento linear da EUA em relação às doses de potássio aplicadas, variando de $0,4293 \mathrm{~kg} \mathrm{ha}^{-}$ ${ }^{1} \mathrm{~mm}^{-1}$ para a menor dose de potássio $\left(30 \mathrm{~kg} \mathrm{ha}^{-1}\right)$ até $0,5463 \mathrm{~kg} \mathrm{ha}^{-1} \mathrm{~mm}^{-1}$ para a maior dose (120 $\mathrm{kg} \mathrm{ha}^{-1}$ ) (Figura 4).

O efeito não significativo da variação das doses de potássio pode ser explicado pelas doses utilizadas, onde até mesmo a menor dose de $30 \mathrm{~kg} \mathrm{ha}^{-1}$ foi suficiente para suprir a extração deste elemento no nível de produtividade alcançado. A taxa de extração de potássio é de 22,95 kg para cada tonelada de fruto, o que daria uma remoção de nutrientes da área de aproximadamente 28,00 
kg de potássio para a produtividade máxima atingida no segundo ano de produção [10]. Outros fatores, portanto, devem estar sendo limitantes ao aumento da produtividade.

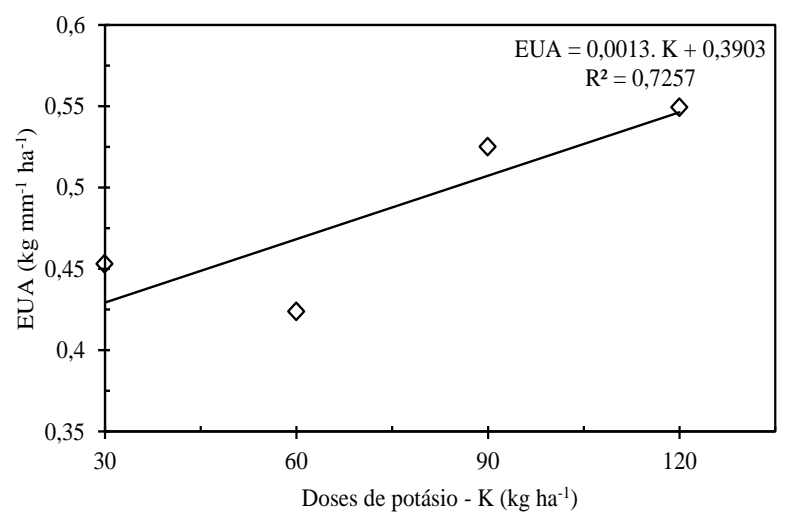

Figura 4: Representação gráfica e equação de regressão da eficiência no uso da água na produção de grãos de pinhão-manso (EUA) em função das diferentes doses de adubação potássica.

\section{CONCLUSÃO}

A irrigação proporciona aumento da produtividade e da eficiência no uso da água do segundo ano de produção de grãos de pinhão-manso, já com relação às dosagens de potássio avaliadas não há reflexo no aumento de produtividade, contudo determina incremento na eficiência no uso da água.

\section{REFERÊNCIAS BIBLIOGRÁFICAS}

1. Anez LMM, Coelho MFB, Albuquerque MCF, Dombroski JLD. Caracterização morfológica dos frutos, das sementes e do desenvolvimento das plântulas de Jatropha elliptica. Revista Brasileira de Botânica. 2005 Apr;28: 563-568, doi: 10.1590/S0100-84042005000300012

2. Arruda FP, Beltrão NEM, Andrade AP, Pereira WE, Severino LS. Cultivo do pinhão-manso (Jatropha curcas L.) como alternativa para o semiárido Nordestino. Revista Brasileira de Oleaginosas e Fibrosas. 2004 Apr:8: 789-799.

3. Carnielli F. O combustível do futuro. Boletim Informativo. 2003 Apr:29, n.1413. <http:// www.ufmg.br/boletim/ bol1413/quarta.shtml>. 05 Mai. 2016.

4. Carvalho CM, Marinho AB, Viana TVA, Valnir Júnior M, Silva LL, Gomes Filho RR. Production componentes of Jatropha under irrigation and nitrogen fertilization in the semiarid region of Ceará. Revista Brasileira de Engenharia Agrícola e Ambiental. 2015 Apr:19(9): 871-876, doi: 10.1590/18071929/agriambi.v19n9p871-876

5. Chaves LHG, Mesquita EF, Araujo DL, França CP. Crescimento, distribuição e acúmulo de cobre e zinco em plantas de pinhão-manso. Revista Ciência Agronômica. 2010 Apr:41(2):167-176, doi: 10.1590/S1806-66902010000200001

6. Dantas AAA, Carvalho LG, Ferreira E. Classificação e tendências climáticas em Lavras, MG. Ciência e Agrotecnologia. 2007 Apr:31(6): 1862-1866, doi: 10.1590/S1413-70542007000600039

7. de Deus FP, Faria MA, Oliveira EL, Castro Neto P. Jatropha seed oil contente and yield under diferente irrigation and potassiun fertilization levels. Revista Engenharia Agrícola. 2012 Apr:32(6): 1089-1096, doi: 10.1590/S0100-69162012000600010

8. Drumond MA, Anjos JB, Paiva LE, Morgado LB, Reis EM. Produção de pinhão-manso no Semiárido Brasileiro. In: Congresso Internacional de Agroenergia e Biocombustíveis, 1, 2007, Teresina. Anais... Teresina: Embrapa Meio Norte, 2007. CD-Rom

9. Evangelista AWP, Melo PC, Oliveira EL, Faria MA. Produtividade e rendimento de sementes de pinhão-manso submetido à irrigação e adubação com OMM-TECH. Engenharia Agrícola. 2011 Apr:31(2):315-323, doi: 10.159/S0100-69162011000200011

10. Fact Fundation. The Jatropha handbook: from cultivation to application. 2010. 117 p. Disponível em: <http://www.fact-foundation.com/media_en/FACT_Jatropha_Handbook_EN_2010_FULL> 
11. Jiang M, Zhang J. Water stress-induced abscises acid accumulation triggers the increased generation of reactive oxygen species and up-regulates the activities of antioxidant enzymes in maize leaves. Journal of Experimental Botany. 2002 Apr: 53:2401-2410, doi: 10.1093/jxb/erf090

12. Laviola BG, Dias LAS. Teor e acúmulo de nutrientes em folhas e frutos de pinhão-manso. Revista Brasileira de Ciência do Solo. 2008 Apr:32(5):1969-1975.

13. Lima RLS, Severino LS, Sampaio LR, Freire MAO, Beltrão NEM, Arriel NHC. Crescimento e teor foliar de nutrientes em mudas de pinhão-manso (Jatropha curcas L.) em substratos contendo cinco materiais orgânicos e fertilizante mineral. Revista de Oleaginosas e Fibrosas. 2009 Apr:13:29-36.

14. Ma F, Hanna MA. Biodiesel production: a review. Bioresource Technology. 1999 Apr:70:1-15, doi: 10.1016/S0960-8524(99)00025-5

15. Nóbrega JA. Crescimento e produção do pinhão-manso adubado e irrigado com água salina sob condições de campo [Dissertação]. Universidade Federal de Campina Grande; 2010. 69 p.

16. Oliveira EL, Faria MA, Evangelista AWP, Melo PC. Resposta do pinhão-manso à aplicação de níveis de irrigação e doses de adubação potássica. Revista Brasileira de Engenharia Agrícola e Ambiental. 2012 Apr:16(6):593-598, doi: 10.1590/S1415-43662012000600001

17. Oliveira JS, Leite PM, Souza LB, Mello VM, Silva EC, Rubim JC, Meneghetti SMP, Suarez PAZ. Characteristics and composition of Jatropha gossypiifolia and Jatropha curcas L. oils and application for biodiesel production. Biomass \& Bioenergy. 2009 Apr:33(3):449-453, doi: 10.1016/j.biombioe.2008.08.006

18. Openshaw K. A review of Jatropha curcas: an oil plant of unfulfilled promise. Biomass \& Bioenergy. 2000 Apr:19(1):1-15, doi: 10.1016/S0961-9534(00)00019-2

19. Purcino AA, Drummond OA. Pinhão-manso. Belo Horizonte: EPAMIG; 1986. 7 p.

20. Sato M, Bueno OC, Esperancini MST, Frigo EP. A cultura do Pinhão-manso (Jatropha curcas L.): Uso para fins combustíveis e descrição agronômica. Revista Varia Scientia. 2007 Apr:07(13):47-62.

21. Sujatha M, Reddy TP, Mahasi MJ. Role of biotechnological interventions in the improvement of castor (Ricinus communis L.) and Jatropha curcas L. Biotechnology Advances. 2008 Apr:26(5):424-435.

22. Silva EM, Silveira JAGS, Fernandes ATBD, Aragão RM. Acúmulo de íons e crescimento de pinhãomanso sob diferentes níveis de salinidade. Revista Ciência Agronômica. 2009 Apr:40(2):240-246.

23. Teixeira LC. Potencialidades de oleaginosas para produção de biodiesel. Informe Agropecuário. 2005 Apr:26(229):18-27.

24. Tikkoo A, Yadav SS, Kaushik N. Effect of irrigation, nitrogen and potassium on seed yield and oil content of Jatropha curcas in coarse textured soils of northwest India. Soil \& Tillage Research. 2013 Apr:13:142-146, doi: 10.1016/j.still.2013.08.001.

25. Trzeciak MB, Neves MB, Vinholes PS, Villela FA. Utilização de sementes de espécies oleaginosas para produção de biodiesel. Informativo Abrates. 2008 Apr:18(1, 2 e 3):30-38. 